\title{
Implementasi Prinsip Ekonomi Gerakan Untuk Pengaturan Tata Letak Fasilitas Kerja Pada Pemrosesan Batu Alam
}

\author{
Luciana Triani Dewi $^{* 1)}$, Marta Hayu Raras Sita Rukmika Sari ${ }^{2)}$, Chandra Dewi ${ }^{3)}$ dan \\ Vincensius Ariyono ${ }^{4)}$ \\ ${ }^{122) 334)}$ Program Studi Teknik Industri, Fakultas Teknologi Industri, Universitas Atma Jaya Yogyakarta \\ Jln. Babarsari No.43 Yogyakarta 55281 \\ e-mail: triani.dewi@mail.uajy.ac.id
}

\begin{abstract}
The layout and arrangement of production facilities is one key to productive and efficient working environment. In planning and setting the layout of the factory, one of the basic principles that should be considered is the planning of work stations. Every operation must be designed in detail by applying economic principles in the movement of goods to and from work station. The study was conducted in a small industry which manufactures natural stone craft in Yogyakarta. Development of work stations design remains to reduce unnecessary activities such as searching and moving equipment activity. Economic principles applied in the development of a facility layout. Evaluation of the layout design was used time study analysis based on the two hand chart before and after improvement of work station layout. Implementation of improved design showed improvement working time for the process which increasing efficiency up to $31.51 \%$. Reduction standard time is achieved because the work methods becomes easier and faster than before.
\end{abstract}

Keywords: facility layout, motion economic, workstation design

\section{Pendahuluan}

Tata letak dan pengaturan area produksi merupakan salah satu kunci untuk menghasilkan lingkungan kerja yang efisien. Tata letak fasilitas merupakan salah satu faktor yang memiliki peran penting dalam peningkatan produktivitas suatu perusahaan dalam melakukan kegiatan produksinya (Tanjung \& Harimansyah, 2014). Tata letak fasilitas yang tepat dapat memperbaiki utilisasi sumberdaya dan meningkatkan efisiensi aliran proses. Hasil penelitian terdahulu menunjukkan biaya terkait penanganan dan pemindahan material dalam proses manufaktur mencapai $20-50 \%$ dari biaya keseluruhan proses dan perencanaan tata letak yang baik dapat mereduksi hingga 10-30\% dari biaya tersebut. Perencanaan tata letak meliputi perancangan, pengaturan tempat dan akomodasi fasilitas-fasilitas dalam lingkungan kerja dengan tujuan untuk minimasi waktu produksi, maksimasi fleksibilitas operasional, maksimasi pergantian bahan dalam proses (turnover WIP) atau maksimasi output sesuai dengan jadwal produksi (Dwijayanti, Dawal, Jamasri, \& Hideki, 2010). Dalam perencanaan dan pengaturan tata letak pabrik, salah satu prinsip dasar yang perlu diperhatikan adalah perencanaan stasiun kerja. Setiap operasi harus dirancang secara rinci dengan menerapkan prinsip-prinsip ergonomi dan ekonomi gerakan dalam pemindahan barang dari dan ke tempat kerja. Setiap stasiun kerja dirancang sebagai bagian terpadu dari rencana keseluruhan. Idealnya rekayasawan tatacara kerja berperan dalam mengerjakannya (Apple, 1990). Fakta umum menunjukkan bawa tata letak stasiun kerja dan tempat kerja yang ergonomis tidak hanya meningkatkan efisiensi proses keseluruhan, tetapi juga dicapai manfaat peningkatan kenyamanan dan pemenuhan kebutuhan psikologis pekerja (Leskova, 2014; Lam, 2013). Aspek manusia perlu diperhatikan dalam perancangan tataletak. Beberapa studi terdahulu menerapkan konsep ekonomi gerakan dalam

\footnotetext{
${ }^{*}$ Correspondance : triani.dewi@ mail.uajy.ac.id
} 
perancangan tata letak. Implementasi konsep ekonomi gerakan dapat diintegrasikan dengan konsep Total Quality Management (TQM) dalam perancangan layout (Paosila, 1999). Integrasi konsep teknik industri termasuk didalamnya melalui studi waktu dan gerakan dalam perancangan layout dapat meningkatkan produktivitas dan fleksibilitas sistem (Ramakrishnan \& Srihari , 2008 ; Sutcu, Tanritanir, Durmusoglu \& Koruca, 2011).

Studi dalam penelitian ini dilakukan di sebuah Industri Kecil Menengah (IKM) yang bergerak dalam pembuatan kerajinan batu alam di Yogyakarta. IKM tersebut belum memiliki stasiun kerja tetap, hal ini membuat pekerja tiap hari harus berpindah mencari tempat yang belum ditempati pekerja lain. Selain itu pekerja juga harus memindahkan semua peralatanperalatannya sebelum memulai pekerjaan. Proses produksi kerajinan batu alam ini dapat dibagi menjadi empat macam proses utama yaitu proses potong, pola, pahat, dan finishing. Dari keempat proses tersebut proses yang dilakukan di tempat yang sama secara kontinyu adalah proses potong, pola dan pahat. Adapun proses finishing dilakukan di tempat terpisah dari ketiga proses yang lain sehingga tidak dibahas dalam studi ini. Oleh karena itu diperlukan stasiun kerja tetap untuk melakukan proses potong, pola dan pahat. Diduga dengan adanya kasus seperti ini, proses pengerjaan menjadi tidak efisien. Sehingga perlu dilakukan perancangan untuk membuat stasiun kerja tetap untuk mengurangi aktivitas yang tidak diperlukan seperti aktivitas mencari dan memindahkan peralatan. Yang dimaksud "tetap" bukanlah bentuk fisik dari stasiun kerja yang dibuat permanen, karena stasiun kerja dapat dibongkar apabila area yang digunakan lebih dibutuhkan untuk aktivitas lain. Kata "tetap" disini merujuk pada prosedur dalam menempatkan peralatan di stasiun kerja. Untuk mendukung perancangan stasiun kerja tetap, perlu dilakukan perancangan tata letak keseluruhan dengan tujuan utama untuk menentukan bagaimana koordinasi dari setiap area produksi diatur sedemikian rupa sehingga mampu menunjang upaya pencapaian efisiensi kegiatan produksi. Dengan melakukan perancangan ulang tata letak fasilitas diharapkan proses produksi menjadi lancar (Tompkins \& White, 1996).

\section{Metodologi}

Studi diawali dengan melakukan observasi dan mengevaluasi tata letak fasilitas dan stasiun kerja yang ada. Pencatatan dilakukan untuk setiap proses yang dilakukan pekerja meliputi jumlah dan kondisi bahan, alat, fasilitas kerja dan metode kerja. Berdasarkan kondisi awal, dilakukan pengembangan peta kerja setempat dan studi waktu dengan jam henti.

Pengembangan rancangan tata letak fasilitas stasiun kerja dengan implementasi prinsipprinsip ekonomi gerakan. Prinsip dari ekonomi gerakan yaitu menganalisis dan mengevaluasi metode kerja guna memperoleh metode kerja yang lebih efisien (Sutalaksana, Anggawisastra, \& Tjakraatmadja, 2006). Prinsip- prinsip yang diterapkan antara lain: (1) gerakan hanya bagian badan yang diperlukan saja untuk melakukan pekerjaan dengan sebaik-baiknya, (2) pekerjaan sebaiknya dirancang semudah-mudahnya dan jika memungkinkan irama kerja harus mengikuti irama yang alamiah bagi si pekerja, (3) diusahakan agar bahan dan peralatan mempunyai tempat yang tetap, (4) tempatkan bahan-bahan dan peralatan di tempat yang mudah, cepat, dan nyaman dicapai serta (5) keseimbangan beban tangan kiri dan tangan kanan.

Tahap evaluasi rancangan dilakukan dengan analisis waktu proses berdasarkan peta tangan kiri tangan kanan sebelum dan sesudah perbaikan tata letak stasiun kerja. Pengembangan rancangan dilakukan hingga dicapai peningkatan produktivitas dan perbaikan gerakan pekerja untuk setiap proses yang ada. Sebagai bahan studi ditunjukkan untuk salah satu proses pembuatan kerajinan batu alam yaitu proses pola pahat. 


\section{Hasil dan Pembahasan}

\subsection{Pengembangan Rancangan Tata Letak Fasilitas Stasiun Kerja dengan Prinsip Ekonomi Gerakan}

Pada umumnya setiap pekerjaan akan lebih mudah dan cepat dikerjakan jika dikerjakan sekaligus oleh tangan kanan dan tangan kiri, oleh karena itu penempatan peralatan-peralatan di stasiun kerja ini dipisah menjadi dua bagian. Pensil, amplas, sapu kecil, palu, serutan, bor tangan, dan gergaji berada di sebelah kanan pekerja sedangkan penggaris siku, alat pahat, dan mal desain diletakkan di sebelah kiri pekerja. Penempatan seperti ini dimaksudkan agar kedua tangan tidak menganggur pada waktu yang bersamaan serta kedua tangan dapat memulai dan mengakhiri gerakan pada saat yang sama. Dengan demikian banyak waktu yang dapat dihemat pada saat melakukan proses potong, pola dan pahat. Selain itu penempatan juga harus disesuaikan dengan kesanggupan dari bagian-bagian tubuh pekerja agar tidak menimbulkan gerakan-gerakan sulit dan berat yang harus dilakukan tubuh. Gambar 1 menunjukkan bahwa tidak ada alat-alat yang ditempatkan di belakang pekerja sehingga tubuh tidak perlu berputar terlalu sering pada saat mengambil peralatan untuk memotong, membuat pola ataupun untuk memahat. Prinsip ekonomi gerakan menyatakan bahan dan peralatan tersebut ditempatkan sedemikian rupa sesuai dengan urutan terbaik dan ditempatkan di tempat yang mudah untuk dicapai/ masih berada dalam daerah kerja baik normal maupun maksimum. Penempatan alat-alat dan perkakas dengan mempertimbangkan area jangkauan optimum pekerja seperti ditunjukkan pada Gambar 2 (Wojcikiewicz, 2013).

Penempatan peralatan diurutkan berdasarkan intensitas pemakaian alat. Alat seperti gergaji diletakkan paling jauh dari pekerja karena gergaji hanya digunakan pada saat proses pemotongan saja, setelah proses potong berakhir gergaji tidak akan digunakan lagi. Beda halnya dengan pensil, pensil ditempatkan paling dekat dengan pekerja karena selain untuk memudahkan dalam pencarian dikarenakan bentuk fisiknya yang kecil, pensil juga memiliki intensitas penggunaan yang tinggi. Pensil dapat digunakan pada saat sebelum dilakukan pemotongan, kemudian digunakan pada saat pembuatan pola, dan dapat juga dibutuhkan pada saat proses pahat berlangsung.
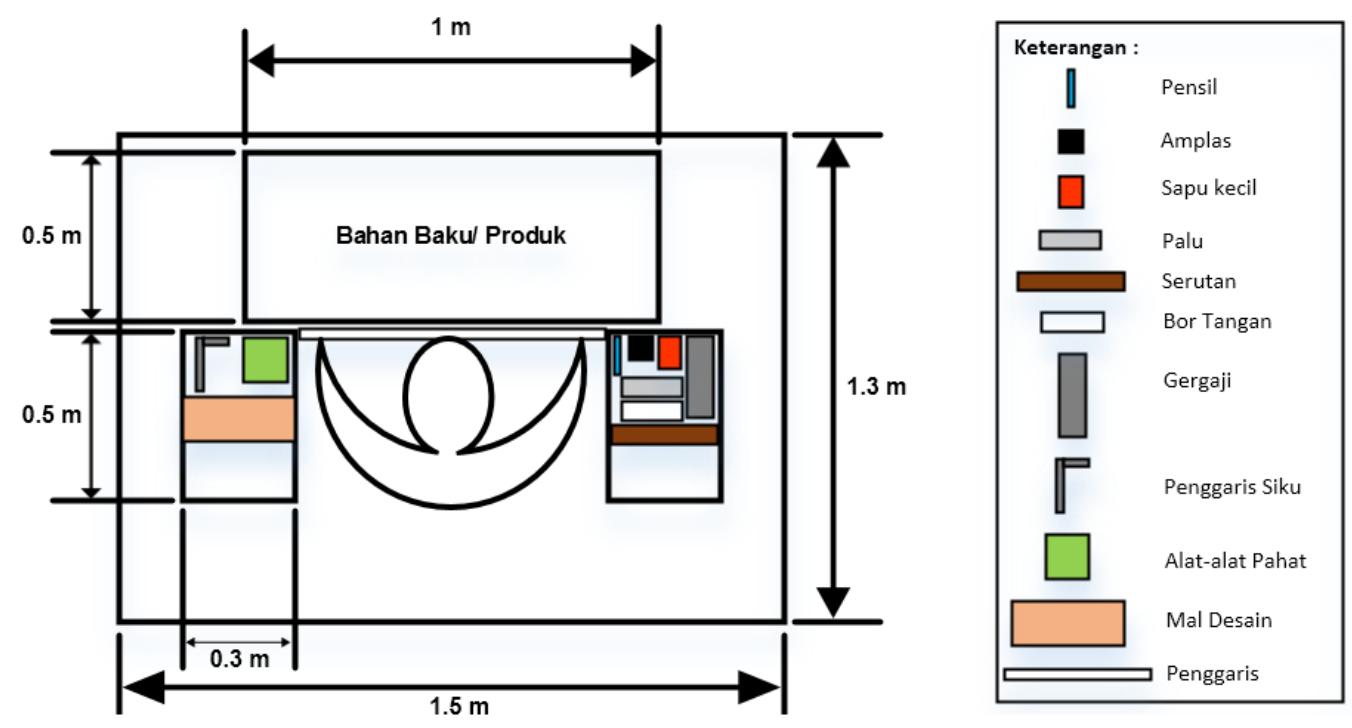

Gambar 1. Rancangan Stasiun Kerja Potong, Pola dan Pahat 


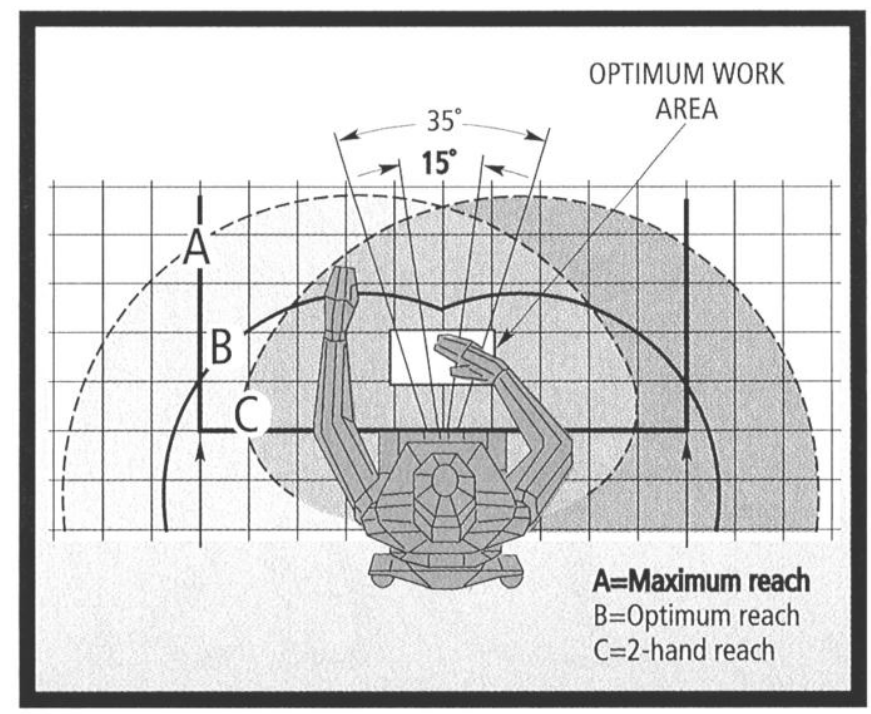

Gambar 2. Area Jangkauan pekerja (Wojcikiewicz, 2013)

Penempatan bahan dan peralatan yang ada pada Gambar 1 bersifat tetap hal ini sesuai dengan prinsip ekonomi gerakan dimana dengan menempatkan bahan dan peralatan ditempat yang tetap akan memudahkan pekerja untuk mengambilnya pada saat diperlukan. Jika tempat sudah tetap dan dikenali, tangan pekerja akan secara otomatis dapat mengambilnya sehingga aktivitas yang tidak diperlukan seperti mencari dapat dikurangi.

Dimensi yang diberikan untuk area bahan baku/ produk sebesar $100 \mathrm{~cm} \times 500 \mathrm{~cm}$ karena disesuaikan dengan ukuran maksimum bahan baku batu putih yaitu $100 \mathrm{~cm} \times 50 \mathrm{~cm} \times 6 \mathrm{~cm}$. Kemudian alas yang digunakan sebagai tempat peralatan memiliki dimensi $50 \mathrm{~cm} x 30 \mathrm{~cm}$, dimensi ini cukup untuk meletakkan peralatan-peralatan baik peralatan yang berada di kanan maupun di kiri pekerja. Kemudian dimensi yang diberikan untuk panjang stasiun kerja sebesar $1.5 \mathrm{~m}$, ukuran ini didapat dari kebutuhan pekerja sebesar $75 \mathrm{~cm}$, ditambah dengan lebar alas peralatan yang berjumlah 2 buah dengan masing-masing berukuran $30 \mathrm{~cm}$, dan ditambah dengan kelonggaran yang diberikan untuk sisi kanan dan kiri stasiun kerja, masing-masing sebesar $7,5 \mathrm{~cm}$. dan dimensi terakhir adalah lebar stasiun kerja, yaitu sebesar 1,3 m didapatkan dari lebar area produksi sebesar $50 \mathrm{~cm}$ ditambah panjang alas peralatan sebesar $50 \mathrm{~cm}$, dan $30 \mathrm{~cm}$ adalah kelonggaran yang diberikan untuk akses keluar masuk stasiun kerja.

\subsection{Evaluasi Metode Kerja Proses Pola Pahat}

Evaluasi dilakukan berdasarkan analisis peta tangan kiri dan tangan kanan proses pola pahat produk loster persegi sebelum perbaikan dan sesudah perbaikan tata letak fasilitas stasiun kerja. Gambar 3 menunjukkan peta tangan kiri tangan kanan kondisi awal dan Gambar 4 menunjukkan peta tangan kiri tangan kanan berdasarkan perbaikan tata letak fasilitas stasiun kerja.

Ringkasan peta tangan kiri dan tangan kanan memperlihatkan perbedaan produktivitas tangan kiri dan tangan kanan antara sebelum dan setelah perbaikan. Keseluruhan ringkasan menunjukkan bahwa produktivitas tangan kiri dan tangan kanan dapat meningkat setelah dilakukan perbaikan. Selain itu ringkasan peta tangan kiri dan tangan kanan tersebut juga menunjukkan perbedaan waktu antara sebelum dan setelah perbaikan, dimana seluruh ringkasan menunjukkan bahwa waktu proses setelah perbaikan lebih kecil dibandingkan dengan sebelum perbaikan. Oleh karena itu, kesimpulan yang dapat diambil dari evaluasi ini adalah adanya penyeimbangan kinerja tangan kiri dan tangan kanan yang diwujudkan dengan usulan perancangan tata letak fasilitas stasiun kerja ini dan reduksi waktu proses pola pahat. 
Pengukuran reduksi waktu proses dilakukan lebih lanjut dan hasilnya dijelaskan pada sub bab berikutnya.

\begin{tabular}{|c|c|c|c|c|c|}
\hline \multicolumn{6}{|c|}{$\begin{array}{l}\text { PETA TANGAN KIRI DAN TANGAN KANAN } \\
\end{array}$} \\
\hline $\begin{array}{l}\text { Pekerjaan } \\
\text { Nomor Peta } \\
\text { Sekarang } \nabla \text { Usulan [ }\end{array}$ & \multicolumn{5}{|c|}{$\begin{array}{l}\text { :Proses Pola pahat Loster Persegi }(15 \mathrm{~cm} \times 15 \mathrm{~cm} \times 5 \mathrm{~cm}) \\
: 3\end{array}$} \\
\hline \multicolumn{3}{|c|}{ TANGAN KIRI } & \multicolumn{3}{|c|}{ TANGAN KANAN } \\
\hline Uraian & $\begin{array}{l}\text { Jarak } \\
(\mathrm{cm})\end{array}$ & $\begin{array}{l}\text { Waktu } \\
\text { (detik) }\end{array}$ & $\begin{array}{l}\text { Waktu } \\
\text { (detik) }\end{array}$ & $\begin{array}{l}\text { Jarak } \\
(\mathrm{cm})\end{array}$ & Uraian \\
\hline Ambil batu potong & 72 & 3 & 3 & 72 & Ambil batu potong \\
\hline Meletakkan batu potong & 40 & 1 & 1 & 40 & Meletakkan batu potong \\
\hline & - & 1 & 1 & 67 & Ambil alat serut \\
\hline $\begin{array}{l}\text { Menyerut Ketebalan } \\
\text { batu }\end{array}$ & 40 & 226 & 226 & 40 & Menyerut ketebalan batu \\
\hline- & - & 1 & 1 & 67 & Meletakkan alat serut \\
\hline 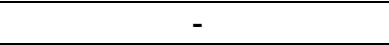 & - & 1 & 1 & 64 & Ambil mal desain \\
\hline Memegang mal desain & 40 & 3 & 3 & 64 & Ambil Pensil \\
\hline Memegang mal desain & 40 & 180 & 180 & 40 & Membuat pola \\
\hline Meletakkan mal desain & 67 & 1 & 1 & 40 & Memegang pensil \\
\hline $\begin{array}{l}\text { Mengambil penggaris } \\
\text { siku }\end{array}$ & 67 & 4 & 4 & 40 & Memegang pensil \\
\hline $\begin{array}{c}\text { Mengukur } \\
\text { menggunakan } \\
\text { penggaris siku }\end{array}$ & 40 & 120 & 120 & 40 & Memegang pensil \\
\hline $\begin{array}{l}\text { Meletakkan penggaris } \\
\text { siku }\end{array}$ & 67 & 1 & 1 & 64 & Meletakkan pensil \\
\hline- & - & 6 & 6 & 64 & Ambil alat pahat \\
\hline Memegang alat pahat & 40 & 3 & 3 & 64 & Ambil palu \\
\hline $\begin{array}{l}\text { Memegang alat pahat } \\
\text { selama proses pahat }\end{array}$ & 40 & 1485.6 & 1485.6 & 40 & $\begin{array}{l}\text { Memegang palu selama } \\
\text { proses pahat }\end{array}$ \\
\hline Meletakkan alat pahat & 67 & 1 & 1 & 64 & Meletakkan palu \\
\hline $\begin{array}{l}\text { Ambil produk selesai } \\
\text { pahat }\end{array}$ & 40 & 2 & 2 & 40 & Ambil produk selesai pahat \\
\hline $\begin{array}{l}\text { Meletakkan produk } \\
\text { selesai pahat }\end{array}$ & 72 & 3 & 3 & 72 & $\begin{array}{c}\text { Meletakkan produk selesai } \\
\text { pahat }\end{array}$ \\
\hline & 732 & 2042.6 & 2.042 .6 & 982 & \\
\hline \multicolumn{6}{|l|}{ Ringkasan: } \\
\hline & \multicolumn{2}{|c|}{ Tangan Kiri } & \multicolumn{2}{|c|}{ Tangan Kanan } & \\
\hline Waktu menganggur & \multicolumn{2}{|c|}{9 detik } & \multicolumn{2}{|l|}{-} & \\
\hline Waktu kerja & \multicolumn{2}{|c|}{2033.6 detik } & \multicolumn{2}{|c|}{2042.6 detik } & \\
\hline Waktu total & \multirow{2}{*}{\multicolumn{2}{|c|}{$\begin{array}{l}\text { 2042.6 detik } \\
99.59 \%\end{array}$}} & \multirow{2}{*}{\multicolumn{2}{|c|}{$\begin{array}{l}2042.6 \text { detik } \\
100 \%\end{array}$}} & \\
\hline Produktivitas & & & & & \\
\hline
\end{tabular}

Gambar 3. Peta Tangan Kiri dan Tangan Kanan Kondisi Awal

\begin{tabular}{|c|c|c|c|c|c|}
\hline \multicolumn{6}{|c|}{$\begin{array}{l}\text { PETA TANGAN KIRI DAN TANGAN KANAN } \\
\end{array}$} \\
\hline \multirow{2}{*}{\multicolumn{6}{|c|}{$\begin{array}{ll}\text { Pekerjaan } & \begin{array}{l}\text { :Proses Pola Pahat Loster Persegi } \\
(15 \mathrm{~cm} \times 15 \mathrm{~cm} \times 5 \mathrm{~cm})\end{array} \\
\text { Nomor Peta } & : 11 \\
\text { Sekarang } \square \text {; Usulan } \boldsymbol{V} & \end{array}$}} \\
\hline & & & & & \\
\hline \multicolumn{3}{|c|}{ TANGAN KIRI } & \multicolumn{3}{|c|}{ TANGAN KANAN } \\
\hline Uraian & $\begin{array}{l}\begin{array}{l}\text { Jarak } \\
(\mathrm{cm})\end{array} \\
\end{array}$ & $\begin{array}{l}\text { Waktu } \\
\text { (detik) }\end{array}$ & $\begin{array}{l}\text { Waktu } \\
\text { (detik) }\end{array}$ & $\begin{array}{l}\begin{array}{l}\text { Jarak } \\
(\mathrm{cm})\end{array} \\
\end{array}$ & Uraian \\
\hline Ambil batu potong & 35 & 2 & 2 & 35 & Ambil batu potong \\
\hline Meletakkan batu & 40 & 1 & 1 & 40 & Meletakkan batu \\
\hline
\end{tabular}




\begin{tabular}{|c|l|l|l|l|c|}
\hline potong & & & & & potong \\
\hline- & - & 1 & 1 & 40 & Ambil alat serut \\
\hline $\begin{array}{c}\text { Menyerut Ketebalan } \\
\text { batu }\end{array}$ & 40 & 226 & 226 & 40 & $\begin{array}{c}\text { Menyerut ketebalan } \\
\text { batu }\end{array}$ \\
\hline- & - & 1 & 1 & 40 & Meletakkan alat serut \\
\hline Ambil mal desain & 40 & 1 & 1 & 43 & Ambil Pensil \\
\hline Memegang mal desain & 40 & 180 & 180 & 40 & Membuat pola \\
\hline Meletakkan mal desain & 42 & 1 & 1 & 40 & Memegang pensil \\
\hline $\begin{array}{c}\text { Mengambil penggaris } \\
\text { siku }\end{array}$ & 46 & 1 & 1 & 40 & Memegang pensil \\
\hline $\begin{array}{c}\text { Mengukur } \\
\text { menggunakan } \\
\text { penggaris siku }\end{array}$ & 40 & 120 & 120 & 40 & Memegang pensil \\
\hline $\begin{array}{c}\text { Meletakkan penggaris } \\
\text { siku }\end{array}$ & 41 & 1 & 1 & 43 & Meletakkan pensil \\
\hline Ambil alat pahat & $\mathbf{4 4}$ & $\mathbf{1}$ & $\mathbf{1}$ & $\mathbf{4 2}$ & Ambil palu \\
\hline $\begin{array}{c}\text { Memegang alat pahat } \\
\text { selama proses pahat }\end{array}$ & 40 & $\mathbf{1 2 0 5 . 9 3}$ & $\mathbf{1 2 0 5 . 9 3}$ & 40 & $\begin{array}{c}\text { Memegang palu } \\
\text { selama proses pahat }\end{array}$ \\
\hline Meletakkan alat pahat & $\mathbf{5 3}$ & $\mathbf{1}$ & $\mathbf{1}$ & $\mathbf{4 2}$ & Meletakkan palu \\
\hline $\begin{array}{c}\text { Ambil produk selesai } \\
\text { pahat }\end{array}$ & 40 & 2 & 2 & 40 & $\begin{array}{c}\text { Ambil produk selesai } \\
\text { pahat }\end{array}$ \\
\hline $\begin{array}{c}\text { Meletakkan produk } \\
\text { selesai pahat }\end{array}$ & 35 & $\mathbf{1}$ & $\mathbf{1}$ & 35 & $\begin{array}{c}\text { Meletakkan produk } \\
\text { selesai pahat }\end{array}$ \\
\cline { 2 - 6 } & 576 & 1745.93 & 1745.93 & 638 & \\
\cline { 2 - 6 }
\end{tabular}

Ringkasan:

\begin{tabular}{|l|l|l|}
\hline & Tangan Kiri & Tangan Kanan \\
\hline Waktu menganggur & 2 detik & - \\
\hline Waktu kerja & 1743.93 detik & 1745.93 detik \\
\hline Waktu total & 1745.93 detik & 1745.93 detik \\
\hline Produktivitas & $99.8 \%$ & $100 \%$ \\
\hline
\end{tabular}

Gambar 4. Peta Tangan Kiri dan Tangan Kanan Setelah Perbaikan

Peta tangan kiri dan tangan kanan setelah perbaikan menunjukkan reduksi jarak dan waktu terjadi untuk beberapa elemen pekerjaan. Penataan bahan dan peralatan dengan prinsip ekonomi gerakan berhasil mereduksi jarak jangkauan untuk pengambilan dan peletakan bahan maupun peralatan. Bahan batu potong yang semula disusun di bagian belakang pekerja memberi jarak $72 \mathrm{~cm}$ dan pekerja harus memutar tubuh saat mengambil. Dengan perbaikan peletakan tumpukan batu potong di area kerja, jarak pengambilan ter-reduksi menjadi $40 \mathrm{~cm}$ dan pekerja tidak perlu memutar tubuh untuk mengambil. Kondisi ini selain mereduksi jarak juga memberi efek perbaikan waktu. Demikian juga untuk elemen pengambilan dan peletakan peralatan pahat. Dengan penataan alat kerja menggunakan prinsip ekonomi gerakan, maka jarak dan waktu pengambilan dan peletakan tereduksi. Proses pemahatan batu juga mengalami reduksi waktu yang cukup signifikan dari 1485,6 detik menjadi 1205,93 detik karena penerapan prinsip ekonomi gerakan yang diterapkan berhasil mengeliminasi gerakan-gerakan yang sulit dan tidak alamiah bagi pekerja.

\subsection{Evaluasi Waktu Kerja Proses Pola Pahat}

Selain peta kerja juga dilakukan studi waktu pada proses pola pahat loster persegi panjang. Pengukuran waktu dilakukan sebanyak tiga puluh data dengan menggunakan jam henti (stop watch) pada proses kerja awal dan proses kerja setelah perbaikan tata letak fasilitas stasiun kerja. Hasil pengukuran waktu sebelum dan sesudah perbaikan ditunjukkan pada Tabel 1. 
Tabel 1. Waktu Standar Kondisi Awal dan Setelah Perbaikan

\begin{tabular}{ccc}
\hline Kondisi awal & Setelah perbaikan & Efisiensi \\
\hline $\begin{array}{c}2042.6 \\
\text { detik/unit produk }\end{array}$ & $\begin{array}{c}1745.933 \\
\text { detik/unit produk }\end{array}$ & $31.51 \%$ \\
\hline
\end{tabular}

Dari hasil perhitungan waktu siklus proses produksi loster persegi panjang sebelum dan setelah perbaikan, dapat dilihat bahwa waktu siklus setelah perbaikan lebih kecil daripada waktu siklus sebelum perbaikan, hal ini membuktikan bahwa adanya efisiensi waktu yang ditimbulkan dari rancangan tata letak fasilitas stasiun kerja yang baru sebesar 31,51\%. Perbaikan waktu ini dicapai karena metode kerja menjadi lebih cepat, mudah dan nyaman bagi pekerja.

\section{Kesimpulan}

Pengembangan rancangan tata letak fasilitas menghasilkan stasiun kerja tetap yang lebih efisien daripada sebelumnya. Prinsip-prinsip ekonomi gerakan diterapkan dalam pengembangan rancangan sehingga pekerjaan menjadi lebih mudah, cepat dan nyaman bagi pekerja. Hasil dari pengaturan tata letak fasilitas stasiun kerja adalah produktivitas pekerjaan tangan kiri dan tangan kanan yang semula rendah menjadi meningkat setelah dilakukan perbaikan dan lebih seimbang beban tangan kiri dan tangan kanan. Hal ini berdampak pada waktu proses yang lebih efisien jika dibandingkan dengan waktu proses sebelum perbaikan. Studi lebih lanjut dapat dilakukan untuk mengintegrasikan perancangan tata letak fasilitas kerja dengan pendekatan ekonomi gerakan ini dengan pendekatan systematic layout planning (SLP). Integrasi kedua pendekatan diharapkan dapat menghasilkan rancangan tata letak yang optimal sekaligus ergonomis bagi pekerja.

\section{Ucapan Terima Kasih}

Ucapan terima kasih disampaikan kepada Kementerian Riset, Teknologi dan Pendidikan Tinggi serta Universitas Atma Jaya Yogyakarta (UAJY) atas dukungan dana penelitian ini melalui Program Penelitian Hibah Bersaing Ristek Dikti tahun 2015.

\section{Daftar Pustaka}

Apple, J. M. (1990). Tataletak Pabrik dan Pemindahan Bahan. Bandung: Penerbit ITB.

Dwijayanti, K., Dawal, S. Z., Jamasri, \& Hideki, A. (2010). A Proposed Study on Facility Planning and Design in Manufacturing Process. Multi Conference of Engineers and Scientists Hongkong, III.

Lam, F. A. (2013). Ergonomic Risk Reduction to Enhance Lean Transformation. Proceedings of the 2013 Industrial and Systems Engineering Research Conference, (hal. 989-997).

Leskova, A. (2014, October - December). Designing of Manual Worksation Structure With Emphasis on Ergonomics. ACTA TECHNIKA Bulletin of Engineering.

Paosila, S. (1999). Applying the Techniques of Time nd Motion Study, Plant Layout and TQM to The Real Situation. Master Theses California State University.

Ramakrishnan, S., \& Srihari,K. (2008). A Novel Method to Re-Layout Facilities Using Industrial Engineering Concepts. Proceedings of the 2008 Industrial Engineering Research Conference, (hal. 655-660)

Sutalaksana, I., Anggawisastra, R., \& Tjakraatmadja, J. (2006). Teknik Perancangan Sistem Kerja. Bandung: Penerbit ITB.

Sutcu1, A., Tanritanir, E., Durmusoglu, B., \& Koruca, H.I. (2011). An Integrated Methodology For Layout Design And Work Organisation In A Furniture Manufacturing Plant. South African Journal of Industrial Engineering May 2011 Vol 22(1) (hal. 183-197)

Tanjung, W., \& Harimansyah, F. (2014). Usulan Perbaikan Tata Letak fasilitas Lantai Produksi Produk Sepatu Perlengkapan Dinas Harian. Journal of Industrial Engineering \& 
$\begin{array}{llll}\text { Management } & \text { Systems, } & \text { 3(1), }\end{array}$ http://repository.ubm.ac.id:8080/335/1/04_Widya.pdf

Tompkins, J., \& White, J. (1996). Facilities Planning. New York: John Willey \& Sons, Inc.

Wojcikiewicz, K. (2003). Seven Keys Factors for Ergonomic Workstation Design. Manufacturing Engineering, July 2003, 45-50 